\section{MoleCULAR CYTOGENETIC EVALUATION OF CHROMOSOMAL MICRODELETIONS: THE EXPERIENCE OF A PUBLIC HOSPITAL IN SOUTHERN BRAZIL}

\author{
Mariluce Riegel ${ }^{1,2}$, Natália Barcellos ${ }^{3}$, Rafaella Mergener ${ }^{2}$, Karen \\ Regina Silva de Souza ${ }^{2}$, Júlio César Loguercio Leite ${ }^{1}$, Rejane Gus ${ }^{1}$, \\ Lilia Maria de Azevedo Moreira ${ }^{4}$, Roberto Giugliani ${ }^{1,2,3}$
}

\begin{abstract}
Introduction: During the past few decades, the number of diseases identified to be caused by chromosomal microdeletions has increased quickly, bringing a new and crucial role for cytogenetics on the diagnosis of these conditions. The purpose of this study was to identify and characterize chromosomal microdeletions associated with malformation syndromes and intellectual disability.
\end{abstract}

Methods: We retrospectively evaluated a consecutive series of samples from a cohort of 598 subjects with clinical symptoms of a microdeletion syndrome, including the deletion of chromosomes 4p16.3, 5p15.2, 5q35, 7q11.23, 8q24.12, 15q11.2, 16p13.3, $17 \mathrm{p} 13.3,17 \mathrm{p} 11.2,2$, and 22q11.2, as investigated by fluorescence in situ hybridization (FISH). Array-based comparative genomic hybridization (array-CGH) was performed on 25 samples with microdeletions.

Results: A total of 598 samples were evaluated from patients whose clinical phenotypes were most indicative of 22q11.2 deletion syndrome (29.10\%), Prader-Willi syndrome (23.41\%), Angelman syndrome (16.89\%), and Williams-Beuren syndrome (14.72\%). In 142 of the samples $(23.75 \%)$, a chromosomal imbalance associated with phenotypic abnormalities was found. The deletion of $7 q 11.23$ was the most frequent $(8.03 \%)$, followed by del22q11.2 (5.68\%) and del15q11.2 (5\%).

Conclusion: Our study reinforces the idea that the effort to improve the capacity to perform molecular cytogenetic investigations associated with a qualified clinical evaluation is crucial for the detection and precise characterization of submicroscopic chromosome deletions, bringing benefits to patients, relatives, and genetic counselors. It also contributes to the continuing education of cytogeneticists and to the knowledge of chromosomal rearrangements associated with genomic disorders.

Keywords: Molecular cytogenetics; microdeletion syndrome; FISH; array-CGH

The phenotypic spectrum observed in some disorders can be attributed to the segmental aneuploidy (deletion, duplication, disruption, or point mutation) of a single dosage-sensitive gene. The lack of a protein encoded by one allele of a gene with a corresponding reduction in the amount of the protein to approximately $50 \%$ is called haploinsufficiency if a decreased level of the protein is insufficient to sustain its normal function, thus leading to an abnormal phenotype. The clinical outcomes of the well-known microdeletion syndromes, which are a consequence of submicroscopic chromosomal deletions that lead to haploinsufficiency, are relatively specific. The phenotypic characteristics are often recognized before the causal microdeletions are identified'. In 1986, Schmikel ${ }^{2}$ proposed the term "contiguous gene" for a group of disorders characterized by microdeletions or microduplications of chromosomal segments associated with clusters of single gene disorders. In contrast to single gene disorders, these conditions, especially those including
Clin Biomed Res. 2014;34(4):357-365

1 Serviço de Genética Médica, Hospital de Clínicas. Porto Alegre, RS, Brazil.

2 Programa de Pós-Graduação em Genética e Biologia Molecular, Universidade Federal do Rio Grande do Sul (UFRGS). Porto Alegre, RS, Brazil.

3 Programa de Pós-Graduação em Medicina: Ciências Médicas, Universidade Federal do Rio Grande do Sul (UFRGS). Porto Alegre, RS, Brazil.

4 Laboratório de Genética Humana e Mutagênese, Instituto de Biologia, Universidade Federal da Bahia (UFBA). Salvador, BA, Brazil.

Corresponding author:

Mariluce Riegel

E-mail: mriegel@hcpa.ufrgs.br Serviço de Genética Médica Hospital de Clínicas de Porto Alegre Rua Ramiro Barcelos, 2350. 90035-003, Porto Alegre, RS, Brasil. 
developmental delay or intellectual disability and congenital developmental abnormalities, result from submicroscopic chromosomal rearrangements encompassing several genes, with at least two of them being dosage-sensitive but, overall, functionally unrelated to each other ${ }^{3}$.

In such contiguous gene deletions (e.g., WilliamsBeuren syndrome [WBS], Prader-Willi syndrome [PWS], Angelman syndrome [AS], and 22q11.2 deletion syndrome [22qDS], the phenotype of the disorder results from an inappropriate dosage of only the dosage-sensitive genes located within the rearranged genomic region. In the past 15 years, technological advances, such as array-based comparative genomic hybridization (array-CGH) ${ }^{4,5}$, have enabled the detection of intermediate-size rearrangements $(>1,000$ base pairs but typically less than 5 megabase pairs [Mb] in length) resulting in a previously unrecognized large-scale form of structural genomic variation known as copy-number variation ${ }^{6,7}$. The most common mechanism of conveying a phenotype by microdeletion or microduplication is altering the copy number of a dosage-sensitive gene(s) located within the rearranged region ${ }^{8,9}$.

Improvements in classical and molecular cytogenetic techniques over the past 40 years have allowed for the increasingly sensitive detection of chromosomal rearrangements, including deletions and duplications related to genomic disorders ${ }^{10}$. Fluorescence in situ hybridization (FISH) was introduced in the late $1980 \mathrm{~s}^{11}$ and can readily detect submicroscopic chromosomal rearrangements that involve regions smaller than 3 $\mathrm{Mb}$. This powerful technique with broad applications in cytogenetics laboratories still has enormous value for retrospective diagnosis and physical mapping of chromosomal rearrangements using cells in suspension stored in a biorepository.

The purpose of this study was to identify and characterize chromosomal microdeletions associated with malformation syndromes and intellectual disability in a cytogenetic laboratory in a public hospital in Southern Brazil.

\section{METHODS}

\section{Subjects}

This retrospective study included cases referred for investigation at the molecular cytogenetics laboratory at the Hospital de Clinicas de Porto Alegre, state of Rio Grande do Sul, Brazil from 1998 to 2013. During this 15 -year period, a total of 1,128 samples were referred for molecular cytogenetic analysis. Of these, 745 cases had a clinical diagnosis of a microdeletion syndrome. From these, 598 cases were included in the present study, as 147 cases did not have available medical records or did not have samples available for investigation with FISH. From the total of selected cases, $93.5 \%$ had been previously analyzed by a karyotype of peripheral blood lymphocytes using the Giemsa banding technique and the nomenclature developed by the International System for Human Cytogenetic Nomenclature ${ }^{12}$. The results of previous cytogenetic analyses were obtained for almost all cases, except for those in which no karyotype was available at the time of selection. To be included in the study, the subjects needed to have clinical symptoms of a specific chromosomal microdeletion ${ }^{3}$. Cases that had only a suspected non-specified clinical microdeletion, cases without medical records, and cases whose samples were not available for investigation by FISH were excluded. Information regarding the cases was retrieved from multiple hospital records, and final cytogenetic and clinical reports were reviewed.

\section{Fluorescence in situ hybridization}

FISH experiments were carried out by standard techniques in all cases using commercially available locus-specific probes (Abbott Laboratories, Des Planes, Illinois, EUA and Cytocell ${ }^{\circledR}$ - Cambridge) for the following regions: $4 \mathrm{p} 16.3$ (WHSCR); $5 \mathrm{p} 15.2$ (D5S23, D5S721); $5 \mathrm{q} 35$ (NSD1); 7q11.2 (ELN/LIMK1/ D7S613); 8q23.3 (TRPS1) and 8q24.11-8q24.12 (EXT1); 15q11-q13 (SNRPN); 16p13.3 (CREBBP); 17p13.3 (LSI1); 17p11.2 (RAI1) and 22q11.2 (TUPLE1). Hybridizations were analyzed with an epifluorescence microscope, and images were captured with a charged-couple device camera. At least 30 cells were analyzed per hybridization. We considered a chromosome region deleted when the FISH signal from the corresponding probe was absent from one of the homologous chromosomes.

\section{Chromosomal microarray analysis}

To validate the use of microarrays for diagnostic purposes at our laboratory and to better define some of the chromosomal rearrangements detected by the FISH analysis, the critical regions of 25 DNA samples, twelve with del4p16.3, nine with del5p15.2, two with del8q24.12, one with del17p13.3, and one with del22q11.2, were further mapped. Wholegenome array-CGH was performed using a 60-mer oligonucleotide-based microarray with a theoretical resolution of $40 \mathrm{~kb}(8 \times 60 \mathrm{~K}$, Agilent Technologies Inc., Santa Clara, CA). Labelling and hybridization were performed following the standard protocols provided by Agilent, version 2011. The arrays were analyzed by the microarray scanner (G2600D) and the Feature Extraction software (v9.5.1) (both from Agilent Technologies). Imaging analyses were performed 
using Cytogenomics v2.0 and Cytogenomics v2.7 with the statistical algorithm ADM-2 and a sensitivity threshold of 6.0.

\section{Ethics review}

This study was approved by the Research Ethics Committee of Hospital de Clínicas de Porto Alegre (HCPA) with number GPPG 10-560 and was conducted in accordance with all current ethical rules ${ }^{13}$.

\section{RESULTS}

From the 598 subjects included in the final sample, 301 (50.33\%) were female and 297 (49.67\%) were male. The age range of the individuals at the moment of FISH analysis varied from 1 day to 49 years (mean 8.2 years; standard deviation 4.0 years). The majority of the subjects originated from the state of Rio Grande do Sul (94\%), and $57 \%$ of these were from small countryside towns. The most relevant clinical features of the patients were collected from multiple hospital records (table 1).

The most common conditions suspected on clinical grounds were 22qDS (29.10\%), PWS (23.41\%), AS $(16.89 \%)$, and WBS $(14.72 \%)$, followed by WolfHirschhorn syndrome (WHS) (3.34\%), Cri-du-Chat syndrome (CdCS) $(2.51 \%)$, Miller-Diecker syndrome (MDS) $(2.51 \%)$, Sotos syndrome (SoS) $(2.34 \%)$, Rubinstein-Taybi syndrome (RTS) (2.17\%), SmithMagenis syndrome (SMS) (1.67\%), and LangerGiedion syndrome (LGS) (1.34\%) (table 2).

Of the 598 cases included in our study, conventional cytogenetic examinations (from peripheral blood) were performed in 559 (93.48\%) of them, and abnormalities were observed in $22(3.93 \%)$ of them (table 1$)$. The deletion of chromosomes 5p15.2 (CdCS) and 4p16.3 (WHS) were the most common abnormalities detected through the karyotype. Abnormal karyotypes in patients with LGS (del8q24.12), 22qDS (del22q11.2), and MDS (del17p13.3) were also reported. For 39 $(6.52 \%)$ patients, the result of the karyotype was not available.

A deletion of $7 q 11.23$ was detected in $8.03 \%$ of the 598 samples, followed by the del22q $11.2(5.68 \%)$, del15q11.2 (5\%), del4p16.3 (2.67\%), del5p15.2 (1.50\%), del17p13.3 (0.33\%), del8q24.12 (0.33\%), and del17p11.2 (0.17\%) (figure 1). FISH investigations were normal for all the samples of patients with SoS and RTS (table 2).

Considering each group of samples separately, FISH analysis identified the del4p16.3 abnormality in $16 / 20(80 \%)$ of WHS samples, the del5p11.2 in $9 / 15(60 \%)$ of CdCS samples, the del7q11.23 in $48 / 88(54.54 \%)$ of WBS samples, the del8q24.12 in $2 / 8(25 \%)$ of LGS samples, the del15q11.2 in $13 / 101$
(12.87\%) of AS samples and in $17 / 140(12.14 \%)$ of PWS samples, the del17p13.3 in 2/15 (13.33\%) of MDS samples, the del17p11.2 in 1/10 (10\%) of SMS samples, and the del22q11.2 in 34/174 (19.54\%) of the 22qDS samples (table 2).

To establish the microarray methodology for diagnostic purposes in our laboratory, array-CGH analysis of fifteen samples with del4p16.3, nine samples with del5p15.2, and one sample with del8q24.12 was performed. The aim was to determine the approximate size of the deleted region and to map the critical region. In the twelve DNA samples where del4p16.3 was confirmed by FISH, eleven showed a terminal $4 p$ deletion between 3.7 and 14.7 $\mathrm{Mb}$, and one showed an $11 \mathrm{Mb}$ interstitial deletion. The nine $5 p 15.2$ classical terminal deletions were between 11.2 and $18.4 \mathrm{Mb}$. The DNA sample from the patient with LGS showed a single copy loss of the long arm of chromosome 8 of $6.43 \mathrm{Mb}$ in size ${ }^{14}$. The map position is based on the UCSC Genome Browser, Feb. 2009, gh19 (NCBI Build GRCH37 reference sequence) (figure 2 ).

This study showed an increase in the number of cases investigated by FISH in all periods of diagnosis: 75 cases from 1998 to 2003, 174 cases from 2004 to 2008 , and 349 cases from 2009 to 2013 (table 3).

\section{DISCUSSION}

Microdeletion syndromes are rare clinical entities caused by chromosomal deletions at or below the level of detection by classical banded cytogenetic studies. These cases may include the sequelae of haploinsufficiency of two or more dominant genes in close proximity ("contiguous gene syndromes"). The characterization of clinically recognizable syndromes can be achieved through a number of cytogenetic and molecular approaches. In Brazil, cytogenetics plays an important role in the diagnosis of these rare diseases. The most commonly used method to demonstrate the occurrence of a deletion in diagnostic laboratories is still FISH with cloned segments present within the deleted segment, followed by multiplex ligation-dependent probe amplification (MLPA) analysis using markers within the critical segments. The main drawbacks of FISH are its failure to detect small deletions and duplications as well as the fact that it is easily affected by the quality of the metaphase spreads. MLPA is less time-consuming and capable of detecting smaller, atypical deletions and duplications in microdeletion syndromes. Compared to FISH, MLPA is also a low cost and technically uncomplicated method for the study of microdeletions, making it a good alternative for many routine applications ${ }^{15}$. However, for retrospective studies where only cells in 
Table 1: Demographic, clinical and standard cytogenetic data obtained from subjects with clinical suspicion of a microdeletion syndrome.

\begin{tabular}{|c|c|c|c|c|c|c|c|c|c|}
\hline Syndrome & OMIM & $\begin{array}{l}\text { Age } \\
\text { range }\end{array}$ & $M$ & $F$ & $\begin{array}{l}\text { Most frequent clinical } \\
\text { features reported in the } \\
\text { hospital records }\end{array}$ & & $\begin{array}{c}\text { Karyotype } \\
\text { N A NA }\end{array}$ & & n \\
\hline AS & 105830 & $1 y-28 y$ & 43 & 58 & $\begin{array}{l}\text { DD/ID, ataxic gait, } \\
\text { inappropriately happy } \\
\text { disposition, hypotonia, } \\
\text { microcephaly, severe speech } \\
\text { impairment, seizures }\end{array}$ & 101 & - & - & 101 \\
\hline CdCs & 123450 & $4 m-35 y$ & 7 & 8 & $\begin{array}{l}\text { High-pitched monotonous cry, } \\
\text { microcephaly, hypertelorism, } \\
\text { epicanthic folds, round face, } \\
\text { severe DD and learning } \\
\text { disabilities }\end{array}$ & 6 & 9 & - & 15 \\
\hline LGS & 190351 & $4 m-20 y$ & 5 & 3 & $\begin{array}{l}\text { Long flat philtrum, ID, } \\
\text { exostosis, cone-shaped } \\
\text { epiphyses }\end{array}$ & 7 & 1 & - & 8 \\
\hline $22 q D S$ & $\begin{array}{l}188400 \\
192430\end{array}$ & NB- 40y & 88 & 86 & $\begin{array}{l}\text { Congenital heart defects/ } \\
\text { conotruncal and aortic arch, } \\
\text { facial dysmorphic features, } \\
\text { DD }\end{array}$ & 152 & 2 & 20 & 174 \\
\hline MDS & 247200 & $2 \mathrm{~m}-30 \mathrm{y}$ & 10 & 5 & $\begin{array}{l}\text { Microcephaly, growth } \\
\text { retardation, DD/ID with } \\
\text { seizures and EEG } \\
\text { abnormalities }\end{array}$ & 14 & 1 & - & 15 \\
\hline PWS & 176270 & $3 m-43 y$ & 68 & 72 & $\begin{array}{l}\text { ID, postnatal hipotonia, } \\
\text { obesity due to food } \\
\text { seeking, hypogonadotropic } \\
\text { hypogonadism }\end{array}$ & 127 & 1 & 12 & 140 \\
\hline RTS & 180849 & $1 y-49 y$ & 8 & 5 & $\begin{array}{l}\text { ID, broad thumbs and toes, } \\
\text { facial dysmorphism }\end{array}$ & 13 & - & - & 13 \\
\hline SoS & 606681 & NB-17y & 7 & 7 & $\begin{array}{l}\text { DD, increased birth length } \\
\text { and weight, excessive growth } \\
\text { in childhood }\end{array}$ & 9 & - & 5 & 14 \\
\hline WBS & 194050 & $1 \mathrm{~m}-39 y$ & 48 & 40 & $\begin{array}{l}\text { DD/ID, overfriendliness, } \\
\text { congenital heart disease, } \\
\text { specially SVAS, facial } \\
\text { characteristics including } \\
\text { bulbous nasal tip, wide mouth, } \\
\text { full lips, full cheeks, and small } \\
\text { widely spaced teeth }\end{array}$ & 88 & - & - & 88 \\
\hline WHS & 194190 & NB-39y & 8 & 12 & $\begin{array}{l}\text { A "Greek-helmet" profile, low } \\
\text { birth weight and postnatal } \\
\text { failure to thrive, microcephaly, } \\
\text { DD }\end{array}$ & 10 & 8 & 2 & 20 \\
\hline SMS & 182290 & $3 y-19 y$ & 5 & 5 & $\begin{array}{l}\text { DD, learning disability, } \\
\text { behavioral disturbance, facial } \\
\text { characteristics }\end{array}$ & 10 & - & - & 10 \\
\hline Total (\%) & - & - & $\begin{array}{c}297 \\
(49.67)\end{array}$ & $\begin{array}{c}301 \\
(50.33)\end{array}$ & DD/ID & $\begin{array}{c}537 \\
(89.79)\end{array}$ & $\begin{array}{c}22 \\
(3.68)\end{array}$ & $\begin{array}{c}39 \\
(6.52)\end{array}$ & $\begin{array}{c}598 \\
(100)\end{array}$ \\
\hline
\end{tabular}

AS: Angelman syndrome; CdCS: Cri-du-Chat syndrome; LGS: Langer Giedion syndrome; 22qDS, 22q11.2 deletion syndrome; MDS: MillerDiecker syndrome; PWS: Prader-Willi syndrome; RTS: Rubinstein-Taybi syndrome; SoS: Sotos syndrome; WBS: Williams-Beuren syndrome; WHS: Wolf-Hirschhorn syndrome; SMS: Smith-Magenis syndrome; OMIM: Online Mendelian Inheritance in man; NB: newborn; m: months; y: years; DD: developmental delay; EEG: electroencephalogram; ID: intellectual disability; SVAS: supravalvular aortic stenosis; M: male; F: female; NA: not available; N: normal; A: abnormal; n: total. 
Table 2: FISH findings in 598 cases with a suspicion of microdeletion associated with the clinical diagnosis.

\begin{tabular}{clccc}
\hline Locus & \multicolumn{1}{c}{ Syndrome } & Total & Non-deleted & Deleted \\
\hline $4 p 16.3$ & Wolf-Hirschhorn & 20 & 4 & 16 \\
$5 p 15.2$ & Cri-du-Chat & 15 & 6 & 9 \\
$5 q 35$ & Sotos & 14 & 14 & 48 \\
$7 q 11.23$ & Williams-Beuren & 88 & 40 & 2 \\
$8 q 24.12$ & Langer-Giedion & 8 & 6 & 13 \\
$15 q 11.2$ & Angelman & 101 & 88 & 17 \\
$15 q 11.2$ & Prader-Willi & 140 & 123 & - \\
$16 p 13.3$ & Rubinstein-Taybi & 13 & 13 & 2 \\
$17 p 13.3$ & Miller-Diecker & 15 & 13 & 1 \\
$17 p 11.2$ & Smith-Magenis & 10 & 140 & 34 \\
$22 q 11.2$ & 22q11.2 deletion & 174 & 456 & 142 \\
Total $(\%)$ & All syndromes & 598 & & \\
\hline
\end{tabular}
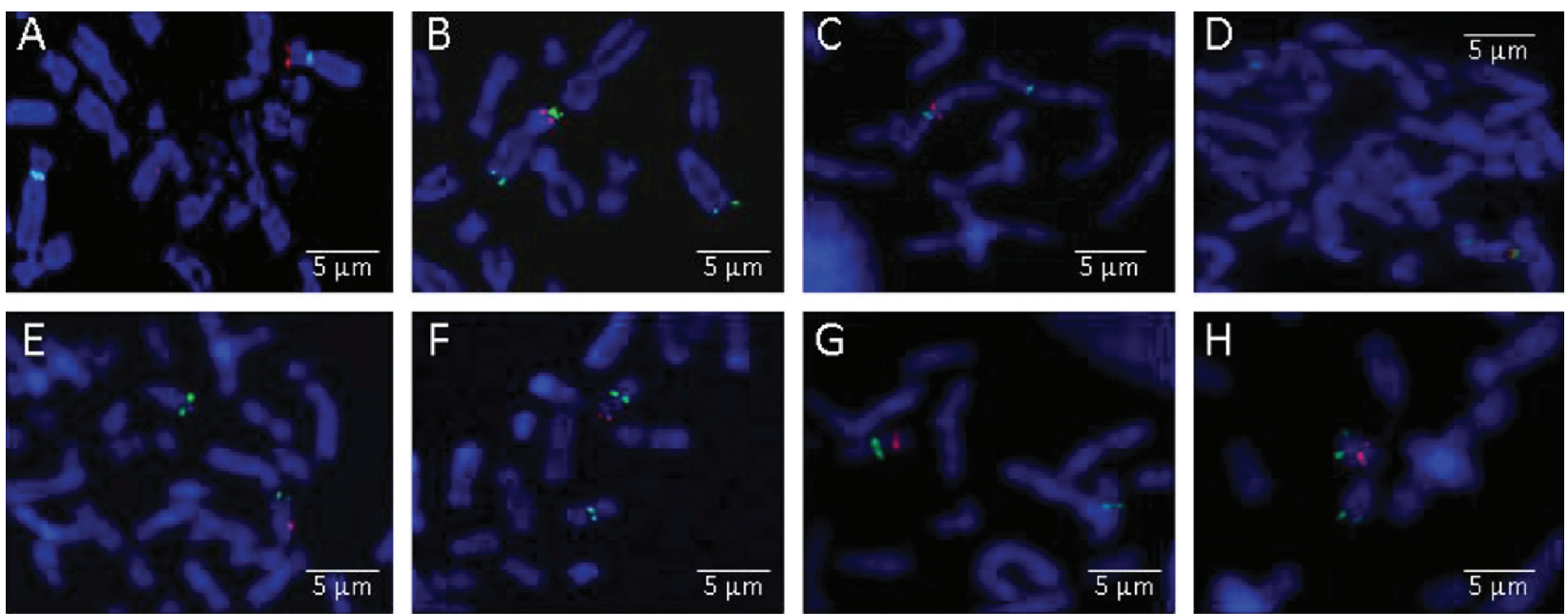

Figure 1: FISH results with locus-specific probes for the microdeletions investigated in this study. Partial metaphases. A: Wolf-Hirschhorn critical region probe. The absence of the red signal on one copy of chromosome 4 (2.67\% of the cases) indicates the deletion of the critical region. B: Cri-Du-Chat critical region. The absence of the green/red signal on one copy of chromosome $5 p$ ( $1.5 \%$ of the cases) indicates deletion of the critical region. C: Elastin gene probe. The absence of the red signal on one copy of chromosome 7 (8.03\% of the cases) indicates $7 q 11.23$ deletion. D: Langer-Giedion syndrome region probe. The blue 8p11-q11 region (control), the red 8q23.3/TRPS1 region, and the green 8q24.1/EXT1 region are shown. The absence of the red and green signals on one copy of chromosome $8(0.33 \%$ of the cases) indicates deletion of both genes. E: Prader-Willi/Angelman region probe. The absence of the red signal ( $5 \%$ of the cases) indicates the deletion of the SNRPN region. F: LIS1 probe. There is a lack of red signal in a patient with Miller-Dieker syndrome $(0.33 \%$ of the cases). G: Smith Magenis region probe. There is a lack of red signal $(0.17 \%$ of the cases), indicating the deletion of the critical region. $\mathrm{H}$ : 22q11.2 deletion syndrome region probe. The absence of the red signal $(5.68 \%$ of the cases) indicates deletion of the critical region. A, F, G: probes from Abbott Molecular Inc., Des Plaines, IL; B, C, D, E, H: probes from Cytocell, Cytocell Ltd., Cambridge, UK. FISH: fluorescence in situ hybridization; TRPS: trichorhinophalangeal syndrome; EXT: exostosin; SNRPN: small nuclear ribonucleoprotein polypeptide N; LIS: lissencephaly. 

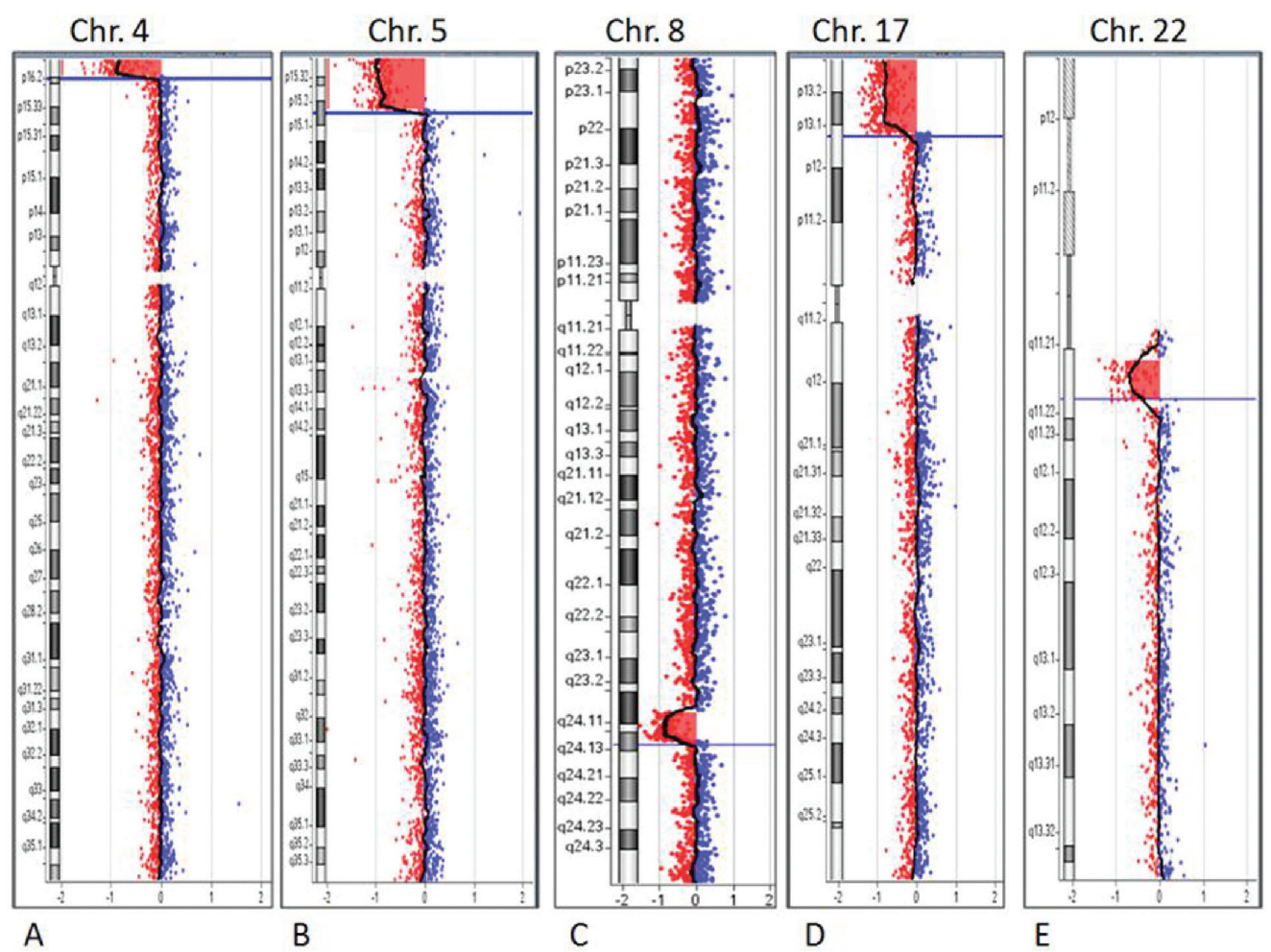

Figure 2: Array-CGH ratio profiles of the chromosomes in five cases with microdeletions using genomic DNA from the patients as test (in red) and DNA from normal subjects as reference (in blue). The test/reference ratio data for each chromosome are shown. Each dot represents a single probe (oligo) spotted on the array. The log ratio of the chromosome probes is plotted as a function of chromosomal position. Copy number loss shifts the ratio to the left (value of about $-1 \mathrm{x}$ ). The ideogram of each chromosome (left margin) shows the location of each probe. The probe log2 ratios were plotted according to genomic coordinates (based on the UCSC Genome Browser, February 2009, NCBI Build 37 reference sequence). A: A 3.7 Mb terminal deletion at chromosome 4p16.3 (red area). B: A 11.2 Mb terminal deletion at chromosome 5p15.33-p15.2 (red area). C: A 5.2 Mb interstitial deletion at chromosome 8q23.3-q24.12 (red area). Array-CGH: array-based comparative genomic hybridization.

Table 3: Samples investigated considering the chromosome critical region according to the period that FISH analysis was performed.

\begin{tabular}{ccccc}
\hline Locus & $\mathbf{1 9 9 8 - 2 0 0 3}$ & $\mathbf{2 0 0 4 - 2 0 0 8}$ & $\mathbf{2 0 0 9 - 2 0 1 3}$ & Total (\%) \\
\hline $4 p 16.3$ & 2 & 4 & 14 & $20(3.34)$ \\
$5 p 15.2$ & - & 3 & 12 & $15(2.51)$ \\
$5 q 35$ & - & 4 & 10 & $14(2.34)$ \\
$7 q 11.23$ & 18 & 22 & 48 & $88(14.72)$ \\
$8 q 24.12$ & - & 5 & 3 & $8(1.34)$ \\
$15 q 11.2$ & 21 & 63 & 157 & $241(40.30)$ \\
$16 p 13.3$ & - & 7 & 6 & $13(2.17)$ \\
$17 p 13.3$ & - & 10 & 6 & $15(2.51)$ \\
$17 p 11.2$ & - & 4 & 88 & $10(1.67)$ \\
$22 q 11.2$ & 34 & 52 & $349(58.36)$ & $174(29.10)$ \\
Total $(\%)$ & $75(12.54)$ & $174(29)$ & & $598(100)$ \\
\hline
\end{tabular}

suspension are available and no DNA samples can be obtained from most patients, as in our study, FISH analysis is an alternative method for the identification of submicroscopic chromosomal deletions.

The deletions of chromosomes 5p15.2 (CdCS) and 4 p16.3 (WHS) were the most common abnormalities detected by chromosome analysis in our samples. This result was expected because these classical deletions can be easily detected in good quality metaphase chromosomes. With the exception of one case of del8q24.12 and one case of del17p13.3, none of the other microdeletions were detected through a 
standard karyotype. Although some microdeletions, such as del8q24.12, del15q11.2, del17p13.3, and del22q11.2, can potentially be detected through a high-resolution karyotype, the majority will not be confidently recognized using only conventional cytogenetic techniques unless, of course, they occur as unbalanced translocations.

In our study, 598 samples were evaluated by $\mathrm{FISH}$, and $142(23.75 \%)$ of them were found to have chromosomal imbalances related to the clinical diagnosis of the subjects. Although among the suspected clinical diagnosis the most common conditions were 22qDS (29.10\%), PWS (23.41\%), AS (16.89\%), and WBS (14.72\%), del7q11.23 was the most frequent abnormality detected by FISH analysis (8.03\%), followed by del22q11.2 (5.68\%) and del15q11.2 (5\%). The overall frequency of microdeletion syndromes in the Brazilian population remains unknown, making comparative studies difficult. The differences between similar studies can also be explained, in part, by the diversity of the samples, the selected criteria, and the methodologies employed ${ }^{16}$.

The fact that the 22qDS, also known as DiGeorge or Velocardiofacial syndrome, corresponded to the most common deletion detected by molecular cytogenetic investigation was not surprise. It is estimated that between two and ten out of every 1,000 live births are affected by some type of cardiac malformation ${ }^{16,17}$, and some congenital heart diseases are associated with the clinical symptoms resulting from del22q112. Speaking of which, del22q11.2 is one of the most common human genetic microdeletions, and the affected individuals have a great probability of undergoing medical interventions and hospitalization throughout their lives.

Nevertheless, FISH has limitations in the detection of microdeletions. Occasionally, patients with small and unusual deletions may escape detection, depending on the specificity of the fluorescent probe. In addition, the cases with gene mutations or imprinting mutations that occur in some microdeletion syndromes like AS, PWS, SoS, MDS, SMS and RTS cannot be detected by FISH. This limitation should be considered when observing that we did not detect any microdeletion among the SoS and RTS cases. We are concerned that some of the cases may still be misdiagnosed. We assume that this study likely failed to detect some microdeletions due to the reduced number of cases in specific groups of subjects and/or due to an incorrect clinical diagnosis. We should also consider that smaller rearrangements in the critical regions in some of our cases were potentially not detected with probes used by FISH. Thus, even if the FISH analysis was normal, the clinical diagnosis of a microdeletion syndrome should not be excluded.
Until relatively recently, high-resolution G-banded karyotyping and FISH studies using probes targeted to known microdeletion loci were considered the gold standard for detecting cytogenetic aberrations ${ }^{18}$. These testing strategies have been strongly challenged by the development of array-CGH, which enables the simultaneous testing of multiple loci for copy number differences. Furthermore, array-CGH has a much higher sensitivity compared to high-resolution karyotyping and can target more loci than FISH in a cost-effective manner, in addition to being more successful than FISH and MLPA in the detection of small chromosomal duplications and atypical microdeletions.

To validate the use of array-CGH methodology in our laboratory for diagnostic purposes and to determine the deletions sizes in some cases, we mapped the critical regions in 25 cases of microdeletions previously detected by FISH. Fifteen samples with del4p16.3, nine samples with del5p15.2, and one sample with del8q24.12 were analyzed. Array-CGH analysis provided a better delineation and more precise mapping of chromosomal deletions compared with FISH. It can be proposed that both methods, used together, are extremely valuable tools for the diagnosis and study of chromosomal rearrangements and that the implementation of both techniques are imperative for the cytogenetic laboratories that provide diagnoses to the Brazilian public health system (Sistema Único de Saúde, SUS). However, the adoption of these methodologies is economically questionable in the context of the SUS medical system.

The clinical evaluation of subjects with microdeletions continues to challenge clinicians and requires a high degree of experience and expertise. Although some steps in finding the diagnosis are highly standardized (for example, database searches, clinical utility gene cards, and standard clinical scores), others are not suitable for standardization. The diagnosis of microdeletion syndromes based only on clinical assessment may be difficult because of the great variability of the manifestations of symptoms, especially relative to the size of the deletion and the expertise of the clinical geneticist ${ }^{19}$.

Our study found an upward trend in the number of microdeletion diagnoses in recent years. More than half $(58 \%)$ of microdeletions were identified between 2009 and 2013, which coincided with the efforts to establish new methods and improve the capacity to study chromosomal abnormalities in our hospital (table 3). Although the number of cases in our study was small for some microdeletions, we observed a significant increase in the number of cases according to the period of the cytogenetic diagnosis. This result likely reflects, among other factors, improved knowledge and practical skills 
obtained through the years regarding the capacity of pediatricians and clinical geneticists to clinically recognize such disorders.

The confirmation of a clinical diagnosis of microdeletion syndromes is crucial for the clinical follow-up of the patients and the genetic counseling of the family. The challenge to the FISH approach is that the examination must be sufficiently indicative of a particular syndrome for the geneticist to know exactly which region(s) and/or chromosome(s) to investigate. There are also syndromes that do not become distinct until a certain age when a particular behavior or clinical manifestation presents. Array-CGH allows professionals to detect chromosomal abnormalities consistent with a genetic syndrome at an earlier age when only a few clinical findings are clear ${ }^{19}$.

Currently, cytogenetic testing in developed countries is likely to use mostly array-CGH technology for the diagnosis of genomic disorders ${ }^{18}$. As the number of recognized genetic syndromes and chromosome abnormalities grows, and, because the clinical characteristics of those syndromes overlap, it becomes more difficult from a clinical examination alone to infer exactly which syndrome is affecting an individual ${ }^{19}$. However, the high cost associated with the cytogenetic molecular methods and the lack of technical skills and professional experience needed for their application are major challenges for developing countries such as Brazil.

Medical management can be greatly impacted by an early diagnosis. Furthermore, it helps patients and their families to understand their disability. Some of the cases presented in our study illustrate the "diagnostic odyssey" faced by the families, with a conclusive diagnosis being reached only after the cytogenetic evaluation was performed. Our study reinforces the idea that the effort to improve the capacity to perform molecular cytogenetic studies in a public hospital brings benefits to patients, relatives and genetic counselors. It also contributes to the continuing education of cytogeneticists and to the knowledge of chromosomal rearrangements associated with genomic disorders.

\section{Acknowledgements}

This study was supported by the CNPq/Brazil grant number 402012/2010-0, CNPq/Brazil 214906/20124, INCT-INAGEMP 573993/2008-4 and FIPE-HCPA GPPG/10-560. The authors appreciate the technical assistance and contributions from colleagues from the Medical Genetics Service who referred patients.

\section{Conflicts of interest}

None to declare.

\section{REFERENCES}

1. Schinzel A, Riegel M, Baumer A. Microdeletion syndromes. In: Nature Encyclopedia of Human Genome. London: Macmillan Publishers; New York: Nature Publishing Group; 2003. p. 950-4.

2. Schmickel RD. Contiguous gene syndromes: a component of recognizable syndromes. J Pediatr. 1986;109(2):231-41. http://dx.doi. org/10.1016/S0022-3476(86)80377-8. PMid:3016222

3. Vissers LE, Stankiewicz P. Microdeletion and microduplication syndromes. Methods Mol Biol. 2012;838:29-75. http://dx.doi. org/10.1007/978-1-61779-507-7_2. PMid:22228006

4. Pinkel D, Segraves R, Sudar D, Clark S, Poole I, Kowbel D, et al. High resolution analysis of DNA copy number variation using comparative genomic hybridization to microarrays. Nat Genet. 1998;20(2):207-11. http://dx.doi.org/10.1038/2524. PMid:9771718
5. Solinas-Toldo S, Lampel S, Stilgenbauer S, Nickolenko J, Benner $A$, Döhner $\mathrm{H}$, et al. Matrix-based comparative genomic hybridization: biochips to screen for genomic imbalances. Genes Chromosomes Cancer. 1997;20(4):399-407. http:// dx.doi.org/10.1002/(SICI)10982264(199712)20:4<399::AIDGCC12>3.0.CO;2-I. PMid:9408757

6. lafrate AJ, Feuk L, Rivera MN Listewnik ML, Donahoe PK, Qi Y, et al. Detection of large-scale variation in the human genome. Nat Genet. 2004;36(9):949-51. http://dx.doi. org/10.1038/ng1416. PMid:15286789

7. Redon R, Ishikawa S, Fitch KR, Feuk L, Perry GH, Andrews TD, et al. Global variation in copy number in the human genome. Nature. 2006;444(7118):44454. http://dx.doi.org/10.1038/ nature05329. PMid:17122850

8. Lupski JR, Stankiewicz P. Genomic disorders: molecular mechanisms for rearrangements and conveyed phenotypes. PLOS
Genet. 2005;1(6):e49. http://dx.doi. org/10.1371/journal.pgen.0010049. PMid:16444292

9. Girirajan S. Genomic disorders: complexity at multiple levels. Genome Med. 2013;5(5):43. PMid:23731576.

10. Shaffer LG, Bejjani BA, Torchia B, Kirkpatrick S, Coppinger J, Ballif BC. The identification of microdeletion syndromes and other chromosome abnormalities: cytogenetic methods of the past, new technologies for the future. Am J Med Genet C Semin Med Genet. 2007;145C(4):335-45. http:// dx.doi.org/10.1002/ajmg.c.30152. PMid:17910076

11. Pinkel D, Straume T, Gray JW. Cytogenetic analysis using quantitative, high-sensitivity, fluorescence hybridization. Proc Natl Acad Sci USA. 1986;83(9):29348. http://dx.doi.org/10.1073/ pnas.83.9.2934. PMid:3458254

12. Shaffer LG, McGowan-Jordan J, Schmid M, editors. ISCN 2013: An 
International System for Human Cytogenetic Nomenclature. Basel: Karger; 2013.

13. Fernandes MS, Ashton-Prolla $P$, Matte $U$, Meurer L, Osvaldt A, Bittelbrunn AC, et al. A Normativa do Hospital de Clínicas de Porto Alegre para o armazenamento e utilização de materiais biológicos humanos e informações associadas em pesquisa: uma proposta interdisciplinar. Rev HCPA. 2010;30(2):169-79.

14. Schinzel A, Riegel M, Baumer A, Superti-Furga A, Moreira LM, Santo LD, et al. Long-term follow-up of four patients with Langer-Giedion syndrome: clinical course and complications. Am J Med Genet A. 2013;161A(9):2216-25. http:// dx.doi.org/10.1002/ajmg.a.36062. PMid:23913778

15. Jehee FS, Takamori JT, Medeiros PF, Pordeus AC, Latini FR, Bertola $\mathrm{DR}$, et al. Using a combination of MLPA kits to detect chromosomal imbalances in patients with multiple congenital anomalies and mental retardation is a valuable choice for developing countries. Eur $J$ Med Genet. 2011;54(4):e42532. http://dx.doi.org/10.1016/j. ejmg.2011.03.007. PMid:21457803

16. Gillum RF. Epidemiology of congenital heart disease in the United States. Am Heart J. 1994;127(4 Pt 1):91927. http://dx.doi.org/10.1016/00028703(94)90562-2. PMid:8154432

17. Hoffman JI, Kaplan S. The incidence of congenital heart disease. $J A m$ Coll Cardiol. 2002;39(12):1890-900. http://dx.doi.org/10.1016/S07351097(02)01886-7. PMid:12084585

18. Riegel M. Human molecular cytogenetics: From cells to nucleotides. Genet Mol Biol. 2014;37(1 Suppl):194-209. http:// dx.doi.org/10.1590/S141547572014000200006. PMid:24764754

19. Emy Dorfman L, Leite JC, Giugliani R, Riegel M. Microarray-based comparative genomic hybridization analysis in neonates with congenital anomalies: detection of chromosomal imbalances. J Pediatr (Rio J). 2015;91(1):59-67. http://dx.doi. org/10.1016/j.jped.2014.05.007. PMid:25203518 